\title{
Pleasantness, Activation, and Negative Affectivity: A Test of Extended UTAUT Model
}

\author{
Sophea Chea \\ Delaware Valley University \\ sophea.chea@delval.edu
}

\author{
Margaret Meiling Luo \\ National Chung Cheng University \\ luo@mis.ccu.edu.tw
}

\begin{abstract}
To better understand how positive and negative emotion influences the intention to use software applications, we introduce two affective constructs namely core affective experience and negative affectivity to the UTAUT (unified theory of adoption and use of technology). We first conducted a pilot study in a lab setting to replicate the UTAUT and the results are encouraging. We then conduced two more lab studies with inexperience and experience users, respectively. The results of the proposed affective augmentation of UTAUT are promising. The proposed relationships between the core affective experience (i.e., activation and pleasantness) and intention to use is significant, similarly the proposed relationship between negative affectivity is also significant. Furthermore, bringing core affective experience into the model makes UTAUT more robust.
\end{abstract}

\section{Introduction}

In the field of Information Systems, user intention to use a technology has been the long-standing and mainstream research question because of its tested predictive power on technology usage behavior which is, in turn, believed to be a good indicator of system success. The studies of the concept and its antecedents are highly based on cognitive paradigm [1, 2, 3]. This cognitive paradigm is influenced by the cognitionattitude-intention-behavior proposed by the theory of reasoned action [4] and the theory of planned behavior [5]. We see at least two shortfalls for the current cognitive paradigm:

(1) Affective aspects of technology adoption have addressed in IS research but there are more aspects of system use that is yet to be understood. Although there are some attempts to bring in the affective related constructs in previous works, such as; perceived enjoyment [6, 7], flow [8, 3], cognitive absorption [9], computer playfulness [10, 11], affect [12], emotional usability [13]; emotions are not given enough weigh in these studies. Furthermore, those affective related constructs are the measures of affective reaction toward the technology. None of the studies addressed the primary core affective experience of user.

(2) IS researchers have made good progress in the identification of cognitive factors and some affective factors that are the determinants of the behavioral intention to use a system. However, those studies span different theoretical roots and they are more appropriate for one context of technological use than the others. Understanding the lack of a unified theory for technology adoption, Venkatesh, Morris, Davis, and Davis [2] proposed a unified theory of acceptance and use of technology (UTAUT) after conducting a rigorous study to validate and cross-validate the model. According to social science citation index, as of Feb 2018, there were 5,927 referred journal articles cited Venkatesh et al. [2] and there are few uses UTAUT with revision as the model of their studies (e.g., [14, 15,16, 17]). With substantial number of work cite UTAUT, the UTAUT model's value is attested. Nevertheless, we further examine the model in its explanation of affective use of system; the conceptual aspect is missing. The recent extension of UTAUTUTAUT 2-has the same issue of lacking evaluation of affectivity (both positive and negative aspects) with system use.

After UTAUT, UTAUT 2 was developed UTAUT 2 was developed for explaining the information service intention. UTAUT 2 guides IS researchers a different orientation from our study where core affectivity shall play a crucial role in adoption decision. Therefore, our research develop along with the logic of UTAUT. To date, we briefly introduce UTAUT 2. In UTAUT 2, key constructs added to UTAUT 2 are hedonic motivation, price value (monetary construct), and habit [18]. Hedonic motivation is intrinsic motivation that drives behaviors [19]. Habit is a process by which a stimulus generates an impulse to act as a result of a learned stimulus-response association. Habit-generated impulses may compete or combine with impulses and inhibitions arising from other sources, including 
conscious decision-making, to influence responses, and need not generate behavior [20]. When software applications is at minimum or no cost, price value would not be a predictor of choice of applications. Typical examples are free mobile apps that are available at Google Play and Apple store. Motivation and habits are not affect which is our focus of attention in this paper; they are active or inactive drivers of behavior that is conceptually different from core affect experience that we would like to explore in this study.

The objective of this study is twofold; first, we attempt to replicate part of UTAUT model that includes behavioral intention and its antecedences. The replication is to assure UTAUT model fit well in our research context, so we may move on to the test of our extending model with core affectivity is added in UTAUT. Secondly, we introduce two core affective constructs to enhance the predictive ability of the model. The two affective constructs are core affective experience, a measure of affective state; and negative affectivity, a measure of affective trait.

\section{Literature review}

\subsection{Theoretical Background and Hypotheses}

In this section we will firstly present the theoretical background of UTAUT grounding in prior literature, secondly we will argue that UTAUT is not really a unified theory because it left out the affective aspects of technology adoption and use. Neither does UTAUT 2. Finally we will present our proposed model and hypotheses taking into account two constructs of emotion, namely, core affective experience and negative affectivity.

Technology Acceptance Model (TAM), which is based on volitional theory of reasoned action, has been the mainstream model in studying technology adoption. However, there are other competing models and their extensions amounted around thousands referred journal articles. They are rooted in different theoretical origins. Totally, there are at least eight competing models of technology adoption. They are: theory of reasoned action (TRA), technology acceptance model (TAM/TAM2), theory of planned behavior (TPB)/decomposed TPB, combined TAM and TPB (CTAM-TPB), motivation model (MM), model of PC use (MPCU), innovation diffusion theory (IDT), and social cognitive theory (SCT). Venkatesh, Morris, Davis, and Davis [2] proposed a unified theory of acceptance and use of technology (UTAUT). The unified model [2] is a result of a rigorous study. They empirically compare and integrate the eight models of Technology Adoption and their extensions into a unified theory. Based on the overlaps of the constructs found in those models, they formulated nine higher level constructs taking into account measurement from conceptually related constructs. All constructs are empirically validated in real organizational settings. Three constructs namely; self-efficacy, attitude, and computer anxiety were finally dropped from the model due to insignificant path coefficients and low contribution of variance explained. Although the model takes into account the use behavior construct, the main focus is the behavioral intention and its antecedents. The UTAUT incorporates four moderators namely; gender, age, experience, and voluntariness of use (See Figure 1). The final model was cross-validated and empirically found to explain the behavioral intention better than any of the competing models (for an elaboration of the model please see [2].

The focus of this study is to replicate part of the UTAUT model that is in the dotted box. In line with the original objective of Venkatesh et al. [2], we are interested in studying the antecedents of behavioral intention to use a system. Due to the cross sectional design and the homogeneity of the subjects (undergraduate students) it is impossible to study the model with its moderators and use behavior. Therefore, we hypothesize the first three hypotheses reflecting the relationships between the three determinants of behavioral intention presented and validated by UTAUT.

H1: Performance expectancy positively influences behavioral intention to use.

H2: Effort expectancy positively influences behavioral intention to use.

H3: Social influence positively influences behavioral intention to use.

\subsection{What is Core Affective Experience?}

Affect and emotion are not as well understood as cognition; therefore, the terminology and definition of concepts are still a problem [21, 22]. Past researches in psychology on the structure of a grab-bag term called emotion have produced a lot of debates on what constitute emotion. Russell and Barrett [23] called for a distinction between, long-term affective disposition (affective trait), momentary core affective experience (state as reported by subject), full-blown prototypical emotional episodes (usually difficult to measure), and affectively charged evaluative reaction (attributed affect and affective quality). Prototypical emotional episode is the full-blown emotional state that is best described a person's emotion at one point in time. To measure prototypical emotional episode one must assess behavior, cognition, experience, and core affect. Thus, core affect is one measure of emotional episode. It is referred to the most elementary consciously accessible affective feelings that need not to be directed at anything [23]. This makes core affect different from attributed affect and perceived affective 
quality. Attributed affect and affective quality [24] are an evaluative reaction toward a stimulus (termed "affect system" by [25]. Due to its accessibility in terms of measurement and its conceptual distinction from attributed affect and perceived affective quality we choose core affect or core affective experience to represent the emotional state in this study.

There are a number of models and measures of core affect or emotional state by using two primary dimensions that form a circular configuration: activated pleasant-deactivated unpleasant and activated unpleasant-deactivated pleasant [26]; positive affect and negative affect [27]; and energy-tired and tensioncalmness [28]. Different measures lead to another debate regarding core affect. It concerns the bipolarity and independence between the two dimensions constituting the structure of emotional state. Barrett and Russell [29] reconciled the bipolar and independent difference by introducing a circumplex model shown in Figure 2. After testing and validating all the competing measures of core affect they conclude; "the structure of affect can have two dimensions, each bipolar, each independent of the other. Once the situation is clearly described, the paradoxes dissolve.” The debates were purely based on naming [29].

Previous studies explore the relationship between core affect and behavioral intention. Volitional model [30] posits that situational affect influence intention. Similarly, model of PC use [31] also argued that positive affect has positive influence on intention to use a PC. Another study by Zhang and Li [32] found that perceived affective quality (a construct related to core affective experience) influences the intention to use a system. Thus, we hypothesize that:

H4: Core Affective Experience influences intention to use

Since core affect consists of two factors independent from each other, we break hypothesis H4 into two sub-hypotheses.

H4a: Pleasantness positively influences intention to use

H4b: Activation positively influences intention to use

\subsection{Negative Affectivity and its influence on Pleasantness}

The concept of negative affectivity has been introduced by Watson and Clark [33]. It is defined as a stable and pervasive individual difference characterized by a tendency to experience aversive emotional states. People with high negative affectivity have negative outlook on life in general. According to Watson and Clark, people with high level of negative affectivity tend to:
- focus more on negative side of oneself

- be less satisfied with self and life in general

- report more negative emotions across time

- emphasize on how individual feel about the world rather than on how to handle oneself in the world.

Levin and Stokes [34] developed an instrument to measure negative affectivity. They use it in their study to test the role of negative affectivity as a dispositional determinant of job satisfaction. In IS field; Woodroof and Burg [35] found that negative affectivity confounds the measure of system satisfaction; Thatcher, and Perrewé [36] incorporated negative affectivity as a predictor of computer anxiety and computer selfefficacy. The concept of self-efficacy is further developed into an updated conceptualization [37].

According to Affective Events Theory [38, 39] affective disposition influences affective reactions. Affective reaction is defined as affective state which is conceptually similar to core affective experience. Thus, we hypothesize that NA is negatively related with core affective experience and specifically with the pleasantness dimension (See Figure 3 for proposed model).

H5: Negative affectivity negatively influence the level of pleasantness.

\section{Method}

We conducted 3 studies: pilot study (proof of concept), study 1 (inexperience users), and study 2 (experience users) to test our proposed model. Below we report the procedures of the 3 studies.

\subsection{Procedures}

\section{Pilot Study}

We employed online survey to collect the data from two sections of introductory statistics classes. The subjects are undergraduate students in the college of business administration of a major U.S. university. They have been introduced to the Microsoft Excel addon statistics software called PHSTAT for two months. Thus they are considered to be experienced users. Furthermore, the use of the software is mandated by the professor.

The survey is conducted in a regular lab schedule for the class to ensure that there is no interruption in students' behavior and emotion. The students were meeting with a moderator in the lecture room prior to going to the lab. The moderator announced the extra credits that will be provided to students who participate in the survey. When they arrived at the computer room, they are assigned randomly to a computer which is already logged on to the survey web page. After 
completing the survey they resumed their lab exercises as usual. Totally there are 67 students filling out the survey and all are valid. We use Partial Least Squares to analyze the data. According to Chin [40] the minimum required sample size is determined by the larger of the two possibilities: (1) the block with the largest number of formative indicators; or (2) the dependent latent variable with the largest number of independent latent variable influencing it. If we use the regression heuristic of 10 cases per predictor, the sample size requirement would be 10 times either (1) or (2), whichever is greater [40]. In our case there is no formative indicator, all items are reflective, so, (1) is ruled out, according to (2) the dependent latent variable that has the largest number of independent latent variables is behavioral intention (see Figure 3) which has 5 independent latent variables. By applying the heuristic rule, the minimum sample size is 50 . Our sample size of 80 is good enough for structural equation modeling with PLS. Another reason that we choose PLS is, Venkatesh et al. [2] used PLS to develop UTAUT. Since our first research objective is to replicate part of UTAUT, using the same software and technique is desirable.

\section{Main studies}

In main studies, inexperience users and experience users were tested. The core affective experience (i.e., Pleasantness and Activation) was also examined with effect size analysis.

\section{Study 1: Inexperience Users}

The sample in study 1 consisted of 43 male and 37 female students (a total of 80) enrolled in an introductory statistics class which is a required core course in the college of business administration of a public university in the U.S.A. They were aged between 19 and 54 with 80 percent of them aged between 19 and 25 years old. Almost all of them are in their junior and senior years of college (only one of them is a sophomore). 53.75 percent of them $(n=43)$ reported that they never used PHStat, 42.5 percent $(\mathrm{n}=$ 34) thought that they are beginner in using PHStat, while the rest of them $(n=3)$ believed that they are at intermediate level of PHStat use.

\section{Study 2: Experience Users}

The objective of the second study is to test the proposed model with experienced users (as in [2]). After the introduction and training of PHStat at the beginning of the semester, students were assigned at least two homework assignment per week. They were given option to use either hand calculation or PHStat for some homework questions. However, for exam purposes, students are required to do some calculations of some homework by hand. The participants were the same students that participated in the study 1.
The sample in study 2 consisted of 40 male and 36 female (a total of 76) enrolled in introductory statistics class which is a required core course in the college of business administration of a public university in the U.S.A. They were aged between 19 and 54 with 80.26 percent of them aged between 19 and 25 years old. All students were in junior and senior years of college. 43.43 percent of them $(n=33)$ reported that they were beginner of PHStat, 52.63 percent $(n=34)$ thought that they were at intermediate level in using PHStat, while 3.95 percent of them $(n=3)$ believed that they were at advanced level of PHStat use. A repeated measure test of those who participated in both study 1 and study 2 $(n=53)$ showed that the level of expertise in PHStat is significantly different between study 1 and study 2 $(\mathrm{p}<0.01)$. Thus the participants in study 2 had a higher experience with PHStat than those in study 1.

\subsection{Measures}

For UTAUT's constructs we use the original items that Venkatesh et al. [2] used to develop and validate the model. The summary of the constructs, their definitions and the instrument are presented in Table 1.

Based on a conceptual and empirical evaluation of core affective experience of Barrett and Russell [29], their students [41] developed a 24-item 5-point-Likertscale. We used the instruction, "right now I am feeling..." to signify the situational state of the subjects' emotion. The items select do not exactly match the adjectives in Figure 2, because many of the items are sub-items that constitute the global items presented in Figure 2. Pleasantness is calculated by subtracting the mean of unpleasant items (irritated, afraid, angry, nervous, frustrated, disappointed, and sad) from mean of pleasant items (excited, joyful, enthusiastic, proud, interested, happy, and satisfied). Similarly, Activation is calculated by subtracting the mean of deactivation items (depressed, tired, quiet, still, relaxed, and clam) from mean of activation items (excited, joyful, enthusiastic, proud, interested, surprised, aroused, irritated, afraid, angry, nervous, and frustrated). This is the standard procedure used by previous studies that adopted the two dimensional structure of affective experience [42, 43, 41)

Negative affectivity is measured using the 24-item 7-point-Likert-scale developed by Levin and Stokes [34]. The instrument has been used in the study of Woodroof and Burg [35] to test the confounding effect of negative affectivity on system satisfaction. There is another measurement of negative affectivity developed by Watson, Clark and Tellegen [44] called PANAS scale, however, we choose the instrument developed by Levin and Stokes [34] because of two reasons. First, the PANAS scale uses similar adjective as in the measurement of core affect, the subjects might get 
confused that we ask the same question twice. Second, the instrument developed by Levin and Stokes has been used in IS field.

\section{Data analysis and results 4.1. Results of the replication Pilot Study}

Partial Least Squares (PLS-Graph, Version 03.00) was used to examine the reliability and validity of the measures. PLS is a structural equation modeling technique that allows researchers to integrate measurement model and structural model [45].

PLS estimates item loadings with t-value. Construct reliability is acceptable when loading is above .70 [46]. Item loadings from a sample of 67 subjects show that all items load substantially high on their assigned construct with relatively small cross-loadings. The loading pattern found in the current work is highly consistent with the study of UTAUT by Venkatesh et al. [2]. Most loadings are above .80 and all of them being above the acceptable level of .70. All loadings are found to be significant at $\mathrm{p}<.001$ level.

In compliance with Venkatesh et al. [2] we employed bootstrapping method to test the validity of the constructs and the significant level of regression path coefficients. The internal composite reliability, AVE (diagonal element), and the inter-construct correlations were estimated and we observe that AVE of each construct is substantially higher than the interconstruct correlations. In PLS, the convergent and discriminant validity are assessed by checking the AVE (average variance extracted) of each construct is larger than its correlation with the other constructs, and that each item has a higher loading on its assigned construct than on the other constructs [47]. In this study both criteria are met. Furthermore, the internal composite reliabilities of all constructs are larger than the acceptable level of .80. Thus, we can conclude that all constructs are reliable and valid.

Table 2 presents the path coefficients (beta coefficients) for each hypothesized relationships and their respective t-value. Variance explained $\left(R^{2}\right)$ for each dependent variable is also reported accompanied by a brief explanation for each hypothesis being tested. The results show that all path coefficients are significant at least at $\mathrm{p}<.05$ level except for the path from SI to BI which is not significant at $\mathrm{p}<.05$. Variance explained for BI is 54 percent (behavioral intention as explained by performance expectancy, effort expectancy, social influence, pleasantness and activation). This level of variance explained is reasonably high. The variance explained for pleasantness by the negative affectivity construct is at 4 percent considering to be relatively small variance explained; however, the path between negative affectivity and pleasantness is significant at $\mathrm{p}<.05$. In PLS studies good model fit is established with significant path coefficients, acceptably high $\mathrm{R}^{2}$ and internal consistency of constructs [48]. Our proposed model satisfies all the requirements for model fit of Structural Equation Modeling using PLS.

Another interesting finding is, after adding the two dimensions of core affective experience, the $\mathrm{R}^{2}$ level increases from .48 to .54 which is relatively high in comparison with the findings of Venkatesh et al. [2] when they didn't include any interaction effects to the model, the $\mathrm{R}^{2}$ level is ranging from, .31 to .42 (PLS results). Furthermore, adding the two affective dimensions to the model makes the path from PE to BI significant. This can be explained by the canceling effects of pleasantness and activation on PE.

\subsection{Results of the Main Studies Study 1}

At the measurement model level, PLS estimates item loadings, residual covariance and inter-construct correlations. To assess reliability and validity of measurement in PLS, researchers typically evaluate a block of indicators' internal composite reliability (ICR) and average variance extracted (AVE). All items load on their assigned construct with relatively small crossloadings. Most loadings are above .80 and all of them are above the acceptable level of .60. All loadings are found to be significant at $p<.001$ level. Selection of items based on item loadings is often recommended in the psychometric literature. The hypothesized relationships in UTAUT are empirically supported except for the relationship between effort expectancy and behavioral intention to use. The results of structural model of the roles of emotion are positive. The two emotional dimensions of core affective experience; activation and pleasantness are hypothesized to be the determinants of behavioral intention. Only the activation dimension significantly influences behavioral intention $(\mathrm{p}<0.01)$. Pleasantness does not significantly influence behavioral intention at $\mathrm{p}<0.05$ but it does at $\mathrm{p}<0.1$.

\section{Study 2}

In study 2, most aspects of UTAUT were successfully replicated with the inclusion of emotional constructs except for the relationship between performance expectancy and behavioral intention. Effort expectancy was found to have no significant influence on behavioral intention for both sub-samples. The two dimensions of core affective experience were found to have significant relationship with behavioral intention in alternative order. Activation significantly predicts behavioral intention only for inexperienced users. NA was found to be a significant predictor of pleasantness in both samples (See Table 4).

4.3. The Roles of Pleasantness and Activation 
The results from both study 1 and study 2 show that CAE has medium effect on behavioral intention and the standardized path coefficients are 0.2 or above; thus, CAE has a place in the model beyond the effects of UTAUT's variables. These findings support findings from previous studies [32], the hypotheses posited in the volitional model of Bagozzi [30], and the risk-asfeeling hypothesis of Loewenstein et al. [50] earlier discussed in the literature review and in the pilot study.

\section{Activation between Study 1 and Study 2}

Test of difference between activation in study 1 and in study 2 yields a significant result $(\mathrm{t}=5.91 ; \mathrm{p}<0.01$, mean of study $1=0.60$, mean of study $2=-0.19$ ) while the test of difference of means for pleasantness is not significant. The result suggests that activation in study 1 is higher than the activation in study 2. To explore what specific adjective words contributes to the different between the activation in study 1 and study 2 , we conduct the tests of mean difference between 21 adjectives that measure core affective experience. The results are shown in Figure 4.

The participants are from three sections of the class in which they meet at different time and days. Thus, the time and date that the core affective experience and other constructs are measured are also different in the three class sections. The first section meets from 12:00 noon to 1:15 PM of Thursday, the second section meet from 1:30 pm to $3: 15$ pm of Thursday, and the third section of the class meet 12: 00 noon to 1:15 of Friday. Since core affective experience might differ in different time of the day and in different day of the week, ANOVA test was performed to test the different in core affective experience measured in different sections of the class. The results show that there was no significant difference in the core affective experience between the three sections of class. So the transitory effect of core affective experience may not be a confounding factor in this study.

The adjectives with a star sign are those that the results of t-tests of mean difference between study 1 and study 2 yield significant results. In general the emotional experience of participants in study 2 were more negative than the emotional experience of participants in study 1 . They were more irritated, less interested, more depressed, less calm, more frustrated, more afraid, angrier, and sadder. Note that depressed and calm are parts of deactivation items while interested, irritated, afraid, angry, and frustrated are parts of activation items, and the activation dimension is calculated by subtracting the mean of deactivation items from the mean of activation items. This is the explanation for the mean difference of activation in the two studies. Another possible explanation for the orientation toward negative emotion in study 2 is the external effects of classroom setting. The second study was conducted in November, three weeks away from final exam. In general during those weeks students were scrambling to get things (i.e. class projects, homework, exams and preparation for final exam) done. The above emotion adjectives can be reasonable associated with this stressful period of college students. Effect Size

To evaluate the level of effect that pleasantness and activation have on behavioral intention, the effect size, $f 2$ is calculated. In Table 3, the effect size of 0.12 for adding the two dimension of core affective experience (CAE) to UTAUT is very close to the cut-off point of 0.15 of medium effect; as a conclusion the effect of CAE is a medium sized effect. Thus, the effect of core affective experience on behavioral intention is meaningful beyond the effect predicted by other variables in UTATU (See Table 3).

\section{Discussion}

The first objective of the present study is to replicate part of the UTAUT model that explained the behavioral intention to use a system. We succeed in replicating the measurement model and part of the structural model. Social influence is found to be not significant in path correlation. However, as pointed out by Venkatesh et al. [2] the role of social influence is controversial, some researchers argued for its inclusion while other argue for its exclusion from the model of technology adoption. In contradiction to previous findings that the influence of social influence tends to be significant in mandatory environment, we found it not significant. The high correlation between PE and SI (.67) might be the culprit for this insignificant relationship. Another culprit might be the characteristics of our sample, according to previous studies, social influence tends to be significant when the sample composes of elder people and women.

The second objective is to test the affective measures and negative affectivity. As for the proposed model we found that the two dimensions of core affective experience are significantly related to the behavioral intention. We also confirmed the hypothesis put forth by affective events theory that affective disposition (trait) is significantly related to core affect (state). This finding also underscores the findings of prior works in information systems discipline paid attention to individual different in systems success [48, 49].

With pilot study, study 1 , and study 2 , the effects of core affective experience and negative affectivity systematically to behavioral intention were found to be salient. This is a crucial findings that is worthy of pursue for the future studies with different software applications. 
Theoretical implication of this study is the important of affect in technology adoption, more specifically the role of situational elementary core affective experience that stems from different sources other than the technology or system itself also come into play in influencing the behavioral intention to use a computer-software. This gives practitioner a good practical implication that the design of the system should take into consideration the emotional aspect of users.

The findings from this study provide avenue for future researches. The UTAUT model has potential of unifying the theory of technology adoption, but more replications are needed to confirm the robustness of model applying across contexts and applications. We suggest the full replication of the model including its moderators and the two affective constructs that we introduced. Understanding the roles of emotion in technology adoption can help explain the adoption behavior better, especially when mobile apps are widely used now and most of the apps are stressed on emotionally intriguing for prolong use.

The limitation of the study is rooted in the crosssectional design and the homogeneity of the student subjects we are unable to replicate UTAUT with its hypothesized moderators, which is one of the most important contributions of the model.

\section{Conclusion}

We introduce two affective construct namely core affective experience and negative affectivity to the UTAUT. In our pilot study, we conduct a lab online survey with 67 undergrad students in a major US university. With the analysis of PLS, we replicate the UTAUT and found that the structural model with three predictors (performance expectancy, effort expectancy, and social influence) of intention is not robust while the two-predictor model (performance expectancy and effort expectancy) does a better job. The results of our proposed affective augmentation of UTAUT are promising. The proposed relationships between the core affective experience and intention to use is significant; similarly the proposed relationship between negative affectivity and pleasantness is also significant. With the results, we conclude that adding the core affective experience and negative affectivity to UTAUA provides us a better understanding on how affectivity plays a role in system use.

We also conducted two studies with inexperience users and experience users, respectively. The result suggests that activation in study 1 (with inexperience users) is higher than the activation in study 2 (with experience users). Meanwhile, there is no significant difference between pleasantness.

Our model can be continuously tested with nonstudent users groups, software applications such as mobile apps or social media use, given these systems are created for pleasure fulfilling and pro-long use.

\section{References}

[1] F. D. Davis, "Perceived Usefulness, Perceived Ease of Use, and User Acceptance of Information Technology”, MIS Quarterly, 13(3), 1989, pp. 319-340.

[2] V. Venkatesh, M. G. Morris, G. B. Davis, F. D. Davis, "User Acceptance of Information Technology: Toward a Unified View”, MIS Quarterly, 27(3), 2003, pp. 425-478.

[3] A. Brandon-Jones and K. Kauppi, "Examining the Antecedents of the Technology Acceptance Model Within Eprocurement”, International Journal of Operations \& Production Management, 38(1), 2018, pp. 22-42.

[4] M. Fishbein and I. Ajzen, Belief, Attitude, Intention and Behavior: An Introduction to Theory and Research, AddisonWesley Publishing Company, Reading, MA, 1975.

[5] I. Ajzen, "The Theory of Planned Behavior", Organizational Behavior and Human Decision Processes, 50(2), 1991, pp. 179-211.

[6] H. Van der Heijden, "User Acceptance of Hedonic Information Systems”, MIS Quarterly, 28(4), 2004, pp. 695704.

[7] C. Yoon, "Extending the TAM for Green IT: A Normative Perspective”, Computers in Human Behavior, 83, 2018, pp. 129-139.

[8] M. Koufaris, "Applying the Technology Acceptance Model and Flow Theory to Online Consumer Behavior", Information Systems Research, 13(2), 2002, pp. 205-223.

[9] R. Agarwal and E. Karahanna, “Time Flies When You're Having Fun: Cognitive Absorption and Beliefs about Information Technology Usage”, MIS Quarterly, 24(4), 2000, pp. 665-694.

[10] J. Webster and J. J. Martocchio, "Microcomputer Playfulness: Development of a Measure with Workplace Implications”, MIS Quarterly, 16(2), 1992, pp. 201-226.

[11] J. Hamari and J. Koivisto, "Why Do People Use Gamification Services?”, International Journal of Information Management, 35(4), 2015, pp. 419-431.

[12] D. R. Compeau and C. A. Higgins, "Computer SelfEfficacy: Development of a Measure and Initial Test”, MIS Quarterly, 19(2), 1995, pp. 189-211.

[13] J. Kim and J. Y. Moon, "Designing Towards Emotional Usability in Customer Interfaces-Trustworthiness of CyberBanking System Interfaces”, Interacting with Computers, 10(1), 1998, pp. 1-29.

[14] V. Venkatesh, J. Y. Thong, F. K. Chan, P. J. H. Hu, and S. A. Brown, "Extending the Two-Stage Information Systems Continuance Model: Incorporating UTAUT Predictors and the Role of Context”, Information Systems Journal, 21(6), 2011, pp. 527-555.

[15] T. Teo and J. Noyes, "Explaining the Intention to Use Technology among Pre-service Teachers: A Multi-Group Analysis of the Unified Theory of Acceptance and Use of Technology”, Interactive Learning Environments, 22(1), 2014, pp. 51-66.

[16] J. C. Oh, and S. J. Yoon, "Predicting the Use of Online Information Services Based on a Modified UTAUT model", Behavior \& Information Technology, 33(7), 2014, pp. 716729. 
[17] Y. K. Dwivedi, N. P. Rana, A. Jeyaraj, M. Clement, and M. D. Williams, "Re-examining the Unified Theory of Acceptance and Use of Technology (UTAUT): Towards a Revised Theoretical Model," Information Systems Frontiers, 2017, pp. 1-16.

[18] V. Venkatesh, J. Y. L. Thong, and X. Xu, "Consumer Acceptance and Use of Information Technology: Extending the Unified Theory of Acceptance and Use of Technology”, MIS Quarterly, 36(1), 2012, pp. 157-178.

[19] E. M. Stevens and F. R. D. Carpentier, "Facing Our Feeling: How Natural Coping Tendencies Explain When Hedonic Motivation Predicts Media Use”, Communication Research, 44(1), 2015, pp. 3-28.

[20] B. Gardner, "A Review and Analysis of the Use of 'Habit' in Understanding, Predicting and Influencing HealthRelated Behavior”, Health Psychology Review, 9(3), 2015, pp. 277-295.

[21] J. P. Forgas, "Mood and Judgement: The Affect Infusion Model (AIM)”, Psychological Bulletin, 117(1), pp. 39-66.

[22] J. A. Russell, "Core Affect and the Psychological Construction of Emotion”, Psychological Review, 110(1), 2003, pp. 145-172.

[23] J. A. Russell and L. Feldman Barrett, "Core Affect, Prototypical Emotional Episodes, and Other Things Called Emotion: Dissecting the Elephant”, Journal of Personality and Social Psychology,76(5), 1999, pp. 805-819.

[24] J. A. Russell and G. Pratt, "A Description of the Affective Quality Attributed to Environments”, Journal of Personality and Social Psychology, 38(2), 1980, pp. 311-322. [25] J. T. Cacioppo, W. L. Gardner, and G. G. Berntson, "The Affect System Has Parallel and Integrative Processing Components: Form Follows Function”, Journal of Personality and Social Psychology, 76(5), 1999, pp. 839-855. [26] R. J. Larsen and E. Diener, "Promises and Problems with the Circumplex Model of Emotion", in Review of Personality and Social Psychology: Emotion, M.S. Clark (Ed.), Sage, Newbury Park, CA, 1992, pp. 25-59.

[27] D. Watson and A. Tellegen, "Toward a Consensual Structure of Mood”, Psychological Bulletin, 98(2), 1985, pp. 219-235.

[28] R. E. Thayer, The Biopsychology of Mood and Activation, Oxford University Press, New York, 1989.

[29] L. Feldmn Barrett and J. A. Russell, "Independence and Bipolarity in the Structure of Current Affect", Journal of Personality and Social Psychology, 74(4), 1998, pp. 967-984. [30] R. P. Bagozzi, "A Field Investigation of Causal Relations among Cognitions, Affect, Intentions, and Behavior”, Journal of Marketing Research, 19(4), 1982, pp. 562-583.

[31] R. L. Thompson, C. A. Higgins, and J. M. Howell, "Personal Computing: Toward a Conceptual Model of Utilization”, MIS Quarterly, 15(1), 1991, pp. 125-143.

[32] P. Zhang and N. Li, "Love at First Sight or Sustained Effect? The Role of Perceived Affective Quality on Users' Cognitive Reactions to Information Technology," in Proceedings of the 25th International Conference on Information Systems, R. Agarwal, L. Kirsch, and J. I. DeGross (Eds), Washington, DC, 2004.

[33] D. Watson and L. A. Clark, "Negative Affectivity: The Disposition to Experience Unpleasant Emotional States”, Psychological Bulletin, 96(3), 1984, pp. 465-490.
[34] I. Levin and J. P. Stokes, "Dispositional Approach to Job Satisfaction: Role of Negative Affectivity”, Journal of Applied Psychology, 74(5), 1989, pp. 752-758.

[35] J. Woodroof and W. Burg, "Satisfaction/Dissatisfaction: Are Users Predisposed?”, Information \& Management, 40(4), 2003, pp. 317-324.

[36] J. B. Thatcher and P. L. Perrewe, “An Empirical Examination of Individual Traits as Antecedents to Computer Anxiety and Computer Self-Efficacy”, MIS Quarterly, 26(4), 2002, pp. 381-396.

[37] D. R. Compeau, J. Correia, J. Thatcher, "Implications of Technological Progress for the Measurement of Technology Acceptance Variables: The Case of Self-efficacy", Paper presented in the International Conference on Information Systems (ICIS) 2017, Seoul, South Korea, 2017.

[38] H. M. Weiss and R. Cropanzano, "Affective Events Theory: A Theoretical Discussion of the Structure, Causes and Consequences of Affective Experiences at Work", in Research in Organizational Behavior, Vol. 18, JAI PRESS INC, Greenwich, 1996, pp. 1-74.

[39] N. M. Ashkanasy, O. B. Ayoko, and K. A. Jehn, "Understanding the Physical Environment of Work and Employee Behavior: An Affective Events Perspective", Journal of Organizational Behavior, 35(8), 2014, pp. 11691184.

[40] W. W. Chin and P. R. Newsted, "Structural Equation Modeling Analysis with Small Samples Using Partial Least Squares”, in Statistical Strategies for Small Sample Research, R. H. Hoyle (Ed.), Thousand Oaks, CA: Sage Publications, 1999, pp. 307-341.

[41] M. G. Seo, L. Feldman Barrett, and J. M. Bartunek, "The Role of Affective Experience in Work Motivation", Academy of Management Review, 29(3), 2004, pp. 423-439. [42] R. Saavedra and S. K. Kwun, "Affective States in Job Characteristics Theory”, Journal of Organizational Behavior, 21(2), 2000, pp. 131-146.

[43] H. M. Weiss, J. P. Nicholas, and C. S. Daus, "An Examination of the Joint Effects of Affective Experience and Job Beliefs on Job Satisfaction and Variations on Affective Experiences Over Time”, Organizational Behavior and Human Decision Processes, 78(1), 1999, pp. 1-24.

[44] D. Watson, L. A. Clark, and A. Tellegen, "Development and Validation of Brief Measures of Positive and Negative Affect: The PANAS Scales”, Journal of Personality and Social Psychology, 54(6), 1988, pp. 1063-1070.

[45] K. A. Bollen, Structural Equations with Latent Variables, Johns Wiley \& Sons, New York, 1989.

[46] R. Thompson, D. W. Barclay, and C. A. Higgins, "The Partial Least Squares Approach to Causal Modeling: Personal Computer Adoption and Use as an Illustration", Technology Studies: Special Issue on Research Methodology, 2(2), 1995, pp. 284-324.

[47] D. Gefen, D. Straub, and M. C. Boudreau, "Structural Equation Modeling Techniques and Regression: Guidelines for Research Practice”, Communications of AIS, 4, pp. 1-78. [48] R. W. Zmud, "Individual Differences and MIS Success: A Review of the Empirical Literature”, Management Science, 25(10), 1979, pp. 966-979.

[49] R. Agarwal and J. Prasad, “Are Individual Differences Germane to the Acceptance of New Information Technologies?”, Decision Sciences, 30(2), 1999, pp. 361-391. 
[50] G. F. Loewenstein, E. U. Weber, C. K. Hsee, and N. Welch, "Risk as Feelings", Psychological Bulletin, 127(2), 1982, pp. 267-286.

[51] Feldman Barrett, L., and Russell, J.A. "Independence and bipolarity in the structure of current affect," Journal of Personality and Social Psychology (74:4) 1998, pp 967-984.

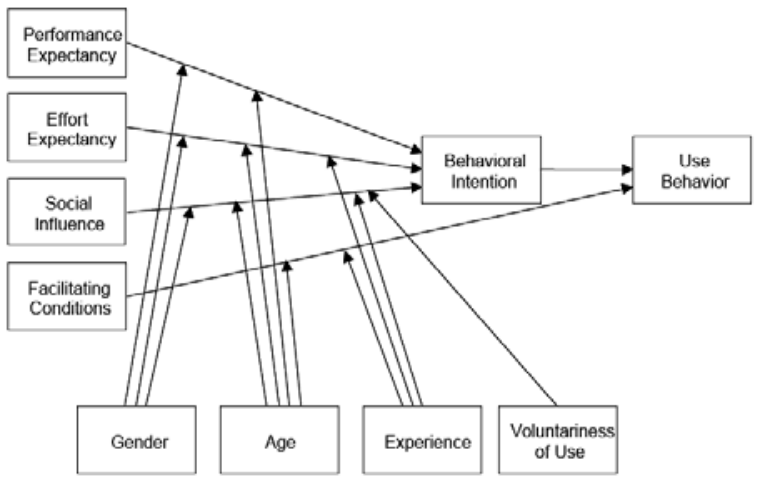

Figure 1: UTAUT Model

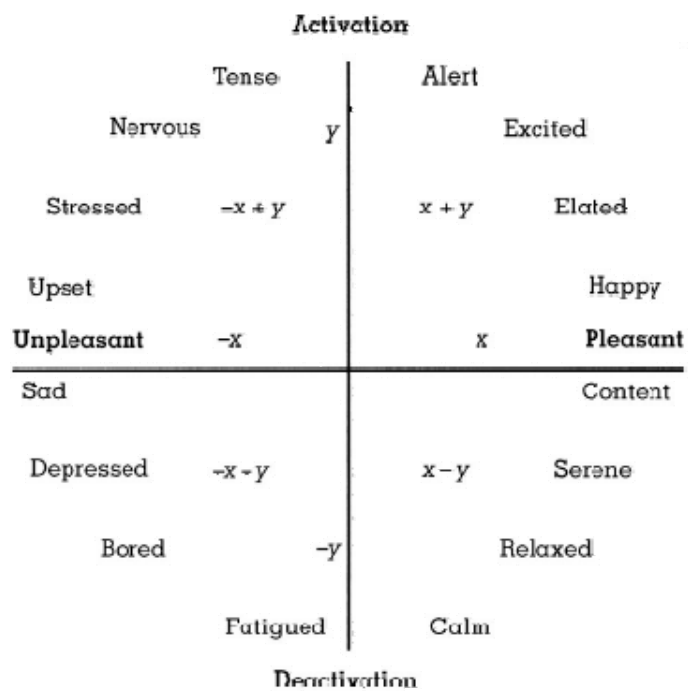

Note: The letters $\mathrm{x}$ and $\mathrm{y}$ represent semantic components of core affect: $\mathrm{x}=$ pleasantness, $\mathrm{y}=$ activation (Feldman Barrett and Russell [51])

Figure 2: Two-Dimensional Structure of Core Affect

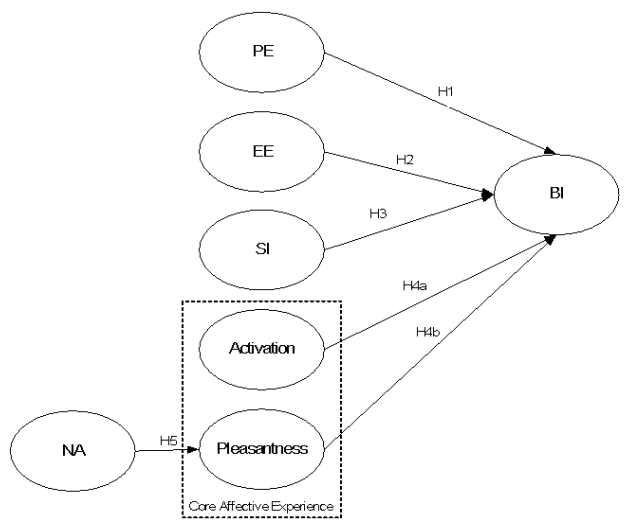

Figure 3: The Proposed Model

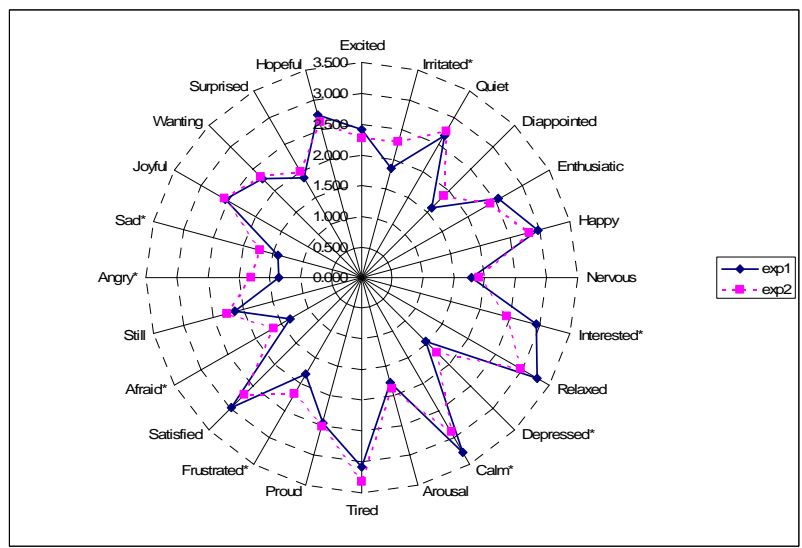

Figure 4: Test of Mean Difference between Core Affective Experience (CAE) in Study 1 and Study 2

Table 1. Constructs' definition and measures

\begin{tabular}{|l|l|l|}
\hline Construct & Operational Definition & Instrument \\
\hline $\begin{array}{l}\text { Performance } \\
\text { Expectancy (PE) }\end{array}$ & $\begin{array}{l}\text { “..the degree to which an individual believe } \\
\text { that using the system will help him or her to } \\
\text { attain gains in job performance.” (Venkatesh } \\
\text { et al. 2003) }\end{array}$ & 4-item scale from Venkatesh et al. (2003) \\
\hline $\begin{array}{l}\text { Effort Expectancy } \\
\text { (EE) }\end{array}$ & $\begin{array}{l}\text { “...the degree of ease associated with the use } \\
\text { of the system.” (Venkatesh et al. 2003) }\end{array}$ & 4-item scale from Venkatesh et al. (2003) \\
\hline Social Influence (SI) & $\begin{array}{l}\text { "the degree to which an individual perceives } \\
\text { that important others believe he or she should } \\
\text { use the new system.” }\end{array}$ & 4-item scale from Venkatesh et al. (2003) \\
\hline
\end{tabular}




\begin{tabular}{|l|l|l|}
\hline $\begin{array}{l}\text { Behavioral Intention } \\
\text { (BI) }\end{array}$ & $\begin{array}{l}\text { Behavioral intention to use the system (Davis } \\
\text { et al., 1989) }\end{array}$ & 3-item scale from Davis et al. (1989) \\
\hline $\begin{array}{l}\text { Core Affective } \\
\text { Experience (CAE) }\end{array}$ & $\begin{array}{l}\text { momentary, elementary feelings of pleasure or } \\
\text { displeasure and of activation or deactivation } \\
\text { (Barrett \& Russell, 1999; Russell, 2003) }\end{array}$ & $\begin{array}{l}\text { 21-item scale Introduced by Barrett \& } \\
\text { Russell (1999) and developed by Seo } \\
\text { (2003) }\end{array}$ \\
\hline $\begin{array}{l}\text { Negative Affectivity } \\
\text { (NA) }\end{array}$ & $\begin{array}{l}\text { a stable and pervasive individual difference } \\
\text { characterized by a tendency to experience } \\
\text { aversive emotional states. (Watson and Clark, } \\
\text { 1984) }\end{array}$ & $\begin{array}{l}\text { 24-item scale developed by Levin and } \\
\text { Stokes (1989) }\end{array}$ \\
\hline
\end{tabular}

Table 2. Summary of Findings (Pilot Study, N=67)

\begin{tabular}{|c|c|c|c|c|}
\hline $\begin{array}{l}\text { Hypothesis } \\
\text { Number }\end{array}$ & Link & $\begin{array}{l}\text { Path Coefficient (t- } \\
\text { value) }\end{array}$ & $\mathrm{R}^{2}$ & Explanation \\
\hline H1 & $\mathrm{PE} \rightarrow \mathrm{BI}$ & $.29(2.96)$ & \multirow[t]{5}{*}{.54} & Significant at $\mathrm{p}<.01$ \\
\hline $\mathrm{H} 2$ & $\mathrm{EE} \rightarrow \mathrm{BI}$ & $.28(2.68)$ & & Significant at $\mathrm{p}<.01$ \\
\hline H3 & $\mathrm{SI} \rightarrow \mathrm{BI}$ & $.15(1.52)$ & & $\begin{array}{l}\text { The link is not significant due to effect of } \\
\text { PE. }\end{array}$ \\
\hline $\mathrm{H} 4 \mathrm{a}$ & Pleasant $\rightarrow$ BI & $.24(2.74)$ & & Significant at $\mathrm{p}<.01$ \\
\hline $\mathrm{H} 4 \mathrm{~b}$ & Activation $\rightarrow$ BI & $-.21(2.42)$ & & Significant at $\mathrm{p}<.05$ \\
\hline H5 & NA $\rightarrow$ Pleasant & $-.20(2.06)$ & .04 & Significant at $\mathrm{p}<.05$ \\
\hline
\end{tabular}

Note : EE effort expectancy, PE performance expectancy, BI behavioral intention to use, and NA negative affectivity.

Table 3. Effect size of pleasantness and activation on behavioral intention (Study 1)

\begin{tabular}{|l|r|r|r|}
\hline Description & R-squared & ${\text { Effect size } \boldsymbol{f}^{\mathbf{2}}}_{\text {Std. Path }}$ \\
\hline UTAUT & 0.517 & - & \\
\hline After adding Pleasantness & 0.534 & 0.04 & 0.14 \\
\hline After adding Activation \& Pleasantness & 0.568 & 0.12 & 0.20 \\
\hline
\end{tabular}

Table 4. Path Analysis Results

\begin{tabular}{|l|l|l|l|}
\hline DV=BI & $\begin{array}{l}\text { Study1 } \\
(\mathrm{N}=80)\end{array}$ & $\begin{array}{l}\text { Study2 } \\
(\mathrm{N}=76)\end{array}$ & Explanation of significant level \\
\hline $\mathrm{R}^{2}(\mathrm{PLS})$ & 0.568 & 0.696 & \\
\hline Adj. $\mathrm{R}^{2}$ & 0.539 & 0.675 & \\
\hline EE & 0.02 & 0.20 & Not significant for both \\
\hline PE & $0.27^{* *}$ & $0.37^{* * *}$ & Significant for both \\
\hline SI & $0.47^{* * *}$ & $0.28^{* *}$ & Significant for both \\
\hline PLN & 0.06 & $0.21^{* * *}$ & Not significant for inexperienced \\
\hline ACT & $0.20^{* *}$ & -0.06 & Significant only for inexperienced \\
\hline DV=PLN (Pleasant) & \multicolumn{3}{|l}{} \\
\hline $\mathrm{R}^{2}(\mathrm{PLS})$ & 0.145 & 0.053 & \\
\hline Adj. $\mathrm{R}^{2}$ & 0.134 & 0.040 & \\
\hline NA & $-0.38^{* * *}$ & $-0.23^{* *}$ & Significant for both \\
\hline
\end{tabular}

Note : EE effort expectancy, PE performance expectancy, SI Social Influence, BI behavioral intention to use, ACT Activation, PLN Pleasant, and NA negative affectivity 